This item was submitted to Loughborough's Research Repository by the author.

Items in Figshare are protected by copyright, with all rights reserved, unless otherwise indicated.

\title{
A pilot study in the application of texture relief for digitally designed facial prostheses
}

PLEASE CITE THE PUBLISHED VERSION

PUBLISHER

Professional Engineering Publishing / @ IMechE

VERSION

VoR (Version of Record)

LICENCE

CC BY-NC-ND 4.0

\section{REPOSITORY RECORD}

Eggbeer, Dominic, Peter L. Evans, and Richard J. Bibb. 2019. "A Pilot Study in the Application of Texture Relief for Digitally Designed Facial Prostheses”. figshare. https://hdl.handle.net/2134/5709. 
This item was submitted to Loughborough's Institutional Repository (https://dspace.lboro.ac.uk/) by the author and is made available under the following Creative Commons Licence conditions.

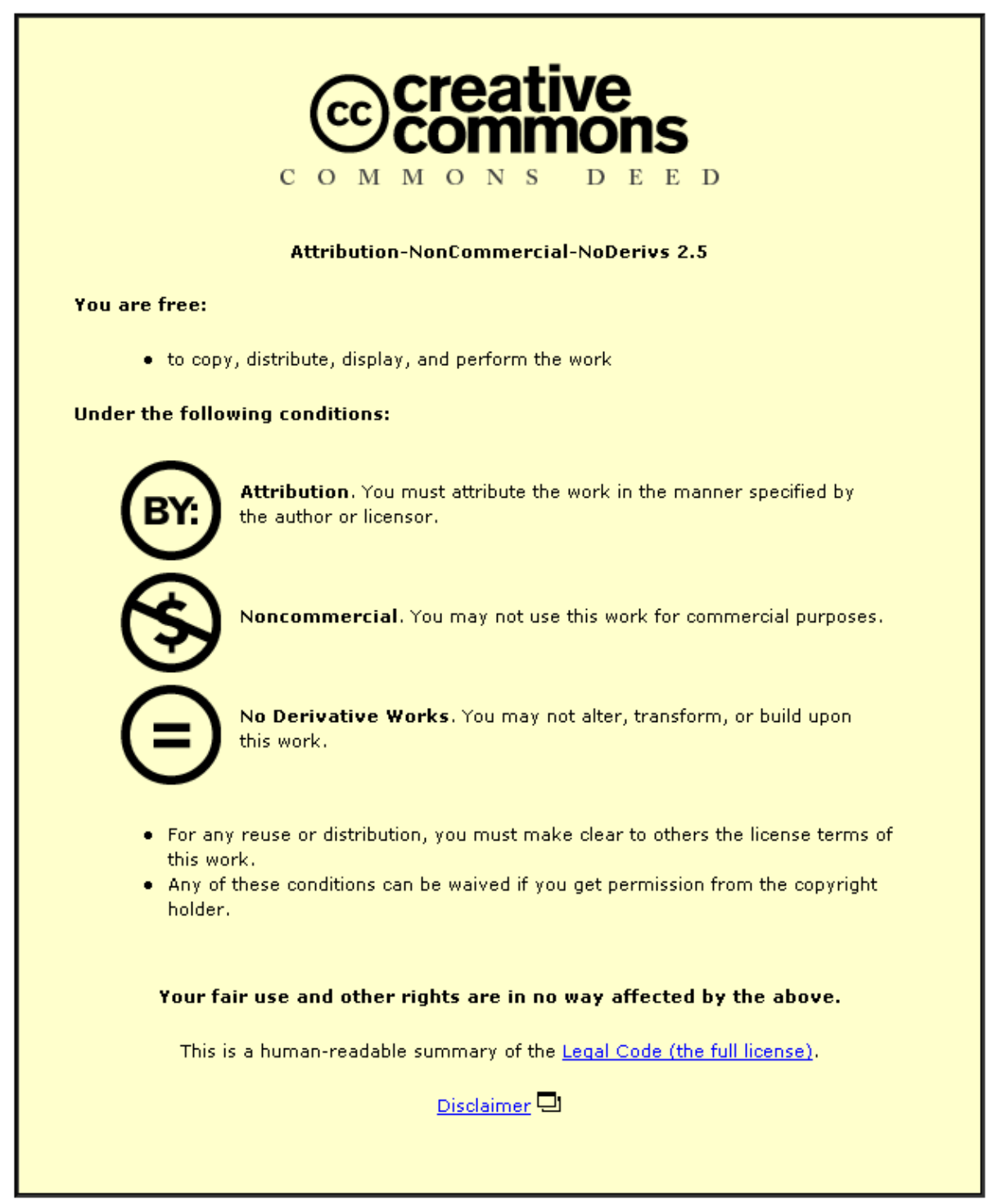

For the full text of this licence, please go to: http://creativecommons.org/licenses/by-nc-nd/2.5/ 


\title{
A pilot study in the application of texture relief for digitally designed facial prostheses
}

D Eggbeer $^{1 *}$, P L Evans ${ }^{2}$, and R Bibb ${ }^{1}$

${ }^{1}$ The National Centre for Product Design and Development Research, The University of Wales Institute, Cardiff, UK

${ }^{2}$ Maxillofacial Unit, Morriston Hospital, Swansea, UK

The manuscript was received on 5 April 2005 and was accepted after revision for publication on 5 May 2006.

DOI: 10.1243/09544119JEIM38

\begin{abstract}
This pilot research aims to identify and assess suitable technologies that may be used to capture, create, and produce fine textures and wrinkles that may be incorporated into computer aided prosthesis design and production techniques. A range of suitable technologies is identified and two methods that may be used in different prosthetic rehabilitation situations are assessed: the creation of three-dimensional relief in a computer aided design environment and the capture of facial anatomy and texture using fringe-projection surface scanning. Patterns were produced using the suitable rapid prototyping processes identified, and these were assessed by a qualified and experienced prosthetist. The suitability of the technologies is commented upon, limitations discussed, and future directions identified.
\end{abstract}

Keywords: computer aided design, digital, prostheses, texture

\section{INTRODUCTION}

Maxillofacial prosthetics is a specialized profession that seeks to meet the needs of patients with various degrees of facial deformity by restoring aesthetic and functional portions of missing tissue using artificial materials. In spite of recent advances in surgery, many cases remain where prosthetic rehabilitation is more suitable and desirable to the patient involved [1].

Patients with conditions resulting from cancer treatment, traumatic injury, congenital deformity, and other diseases that cause significant tissue damage are served. Although facial prostheses are often the most challenging, maxillofacial prosthetists and technologists (MPTs) are also required to produce other body parts such as hands, nipples, and feet. Figure 1 shows some examples.

Factors that contribute to the aesthetic success of prostheses include colour match, contours, and texture [2]. Each of these factors is conventionally assessed by eye and carved by hand in wax on a plaster replica of the patient's defect. Contours of the

* Corresponding author: The National Centre for Product Design and Development Research, The University of Wales Institute, Western Avenue, Cardiff CF5 2YB, UK. email: deggbeer-pdr@ uwic.ac.uk prosthesis are established first, typically with the patient present for test fittings. Details are gradually refined using warmed metal sculpting tools to define creases, folds, and smaller skin details that match the topography and texture of the surrounding anatomy. Skin texture may be added in a number of ways, including stippling with a toothbrush, orange peel, or gauze. When the wax sculpting is complete, a multipart plaster mould is made. This picks up the surface texture detail of the wax carving and transfers it to the final prosthesis. Once set, the wax is boiled away and the mould is packed with silicone elastomer colour matched to the patient's skin. Coloured flocking may be added to replicate superficial capillaries and veins. The silicone is heated under pressure to produce the cured material. Prosthesis construction typically takes $2-3$ days.

In recent years there has been increased interest in the application of advanced three-dimensional scanning and computer aided design and rapid prototyping (CAD/RP) technologies to improve aesthetics and reduce construction time. Whereas RP technologies have been exploited in maxillofacial surgery for many years, the benefits remain relatively underdeveloped in facial prosthetics [3]. Recent advances have provided an increased opportunity for the profession to benefit from these technologies, which is reflected in the increased research interest 


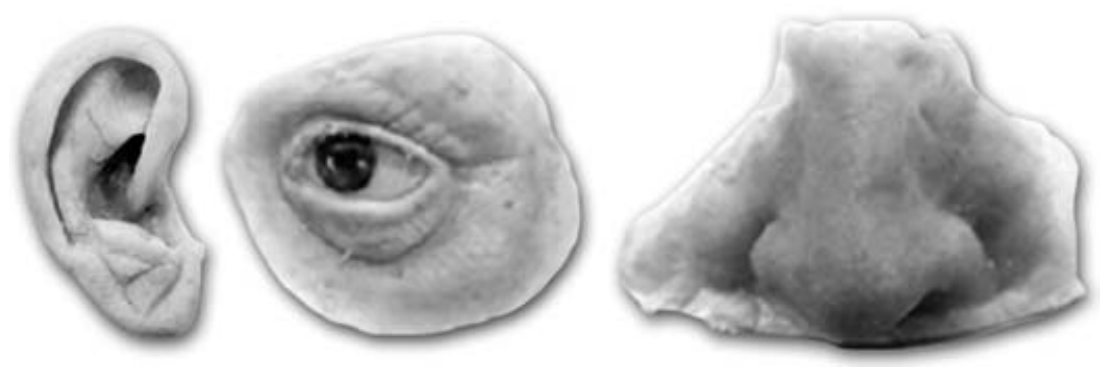

Fig. 1 Examples of facial prostheses

in the topic [4-12]. However, most research into the application of CAD and RP technologies to date has focused on the capture and creation of the overall shape and does not consider the smaller details that make a prosthesis more visually convincing. Given the importance of texture and wrinkling in achieving a natural looking, realistic result, it should be considered when developing new techniques and Fig. 2 outlines how texture man be incorporated.

The objectives of this pilot research are to:

(a) identify suitable levels of skin texture;

(b) identify suitable digital methods of capturing, creating, and reproducing skin texture;

(c) evaluate subjectively the technologies identified;

(d) use the results to direct future research and identify methods for quantifying specifications against which technologies may be assessed.

\section{DEFINITION OF SKIN TEXTURE}

Visible skin texture may be classified according to the orientation and depth of the lines [13]. Primary and secondary lines form a pattern on the skin surface and are only noticeable on closer observation. They typically form a criss-cross, polygonal pattern 20-200 $\mu \mathrm{m}$ deep [14]. The back of the hand often shows a good example. It has been suggested that the term 'wrinkle' should apply when an extension of the skin perpendicular to the axis of the skin surface change leaves a marked line representing the bottom of the wrinkle [13]. Further, an assessment scale that was subsequently used to assess and quantify deep facial wrinkles has been developed by Lemperle et al. [15]. Wrinkles from various facial locations were subjectively graded from 0 to 5 by dermatologists: 0 was described as no wrinkles and 5 denoted very deep wrinkles or redundant folds. Following visual grading, the wrinkles were then measured using profilometry, and the results correlated. This produced a graded wrinkle scale table with associated depth of wrinkle values for the various facial locations. Using this scale, a nasolabial wrinkle (side of the nose) with a grading of 1 would correlate to a wrinkle depth of less than $0.2 \mathrm{~mm}$, and a grading 5 would be greater than $0.81 \mathrm{~mm}$ in depth. This varied with other facial locations, with the minimum measured depth being $0.06 \mathrm{~mm}$ and the maximum being $0.94 \mathrm{~mm}$. The proposed margins on the scale ranged from $>0.1 \mathrm{~mm}$ to $<0.81 \mathrm{~mm}$.

\section{IDENTIFICATION OF SUITABLE TECHNOLOGIES}

\subsection{Specification requirements}

A number of criteria may be identified to aid in technology selection. For data capture, these may be summarized as accuracy, resolution, area of capture, and speed of capture. For CAD tools, these may be summarized as intuitive ability to manipulate anatomical forms, ability to apply texture relief, and output of suitable files for fabrication. For pattern production, these may be summarized as resolution, production volume capabilities, production speed, and material compatibility.

Based upon the rating scale developed by Lemperle et al. [15], potential digital technologies must be capable of capturing, creating, and reproducing wrinkle and texture details with a minimum depth of $0.1 \mathrm{~mm}$. This means that the actual positional accuracy of the surface data captured should be within a much higher tolerance, around $\pm 0.02 \mathrm{~mm}$. However, the most important specification is resolution or point density of the captured data, which should be sufficient to describe complex surfaces within the positional tolerance. In addition, the CAD software should be capable of creating and manipulating complex anatomical forms, and the RP process should be capable of producing patterns to the required resolution in a material compatible with current prosthetic methods $[\mathbf{8}, \mathbf{1 1}, \mathbf{1 2}]$.

\subsection{Capture of anatomical contours and skin textures}

Past research has considered a number of topographic and tomographic capture methods: non- 
contact optical laser/structured white light scanning, computer tomography (CT), and magnetic resonance (MR) [4-13]. Previous research highlights the advantages and limitations of each of these techniques. Both CT and MR capture cross-sections through the body in the form of pixel-based images. The resolution of these is relatively low (typical pixel size $0.25-0.5 \mathrm{~mm}$ and image size $512 \times 512$ pixels), so that if these data were to be used it would be necessary to add texture relief during the CAD stages. Noncontact, optical scanning techniques have been used to capture anatomical forms in previous research with varying degrees of success $[\mathbf{5}-\mathbf{7}, \mathbf{9}, \mathbf{1 0}]$. Modern structured white light scanning technologies are capable of extremely high tolerances that meet or exceed the requirements. In addition, specialist three-dimensional texture scanners are available and are used by dermatologists and cosmetists to assess skin surfaces [16, 17]. Table 1 provides a comparison between scanning technologies that have been used or are advertised for use in medicine. While it is recognized that accuracy and resolution are also dependent on factors such as surface quality, the effects of noise, and post-capture processing of data, it is possible to identify potentially suitable technologies.

Digital photography, impression taking, and pad printing may also be used to capture close-up twodimensional images of the skin, which can then be used to create three-dimensional relief using CAD software. This is outlined in section 3.3.

\subsection{Computer representation and manipulation of skin textures}

Three-dimensional CAD packages have traditionally been developed for two main markets: engineering design and computer gaming/animation. Engineering design $\mathrm{CAD}$ has been developed to define exacting but primarily geometric shapes, and the modelling methods employed limit the ability to define anatomical forms, folds, sharp radii, and textures. Textures are not normally required for these applications. Three-dimensional computer gaming and animation software (such as 3D Studio by Discreet) exhibits many of the same limitations as engineering $\mathrm{CAD}$, but typically allows a greater freedom for freeform surface manipulation. However, textures are normally represented by wrapped two-dimensional images, creating an illusion of texture rather than true three-dimensional relief. This 'wrapped' texture cannot be physically reproduced using RP techniques.

Alternative methods of true three-dimensional texture creation have been explored [18]. Jewellery design software such as ArtCAM (Delcam plc) incorporates tools to map three-dimensional textures around a CAD model [18]. However, ArtCAM and

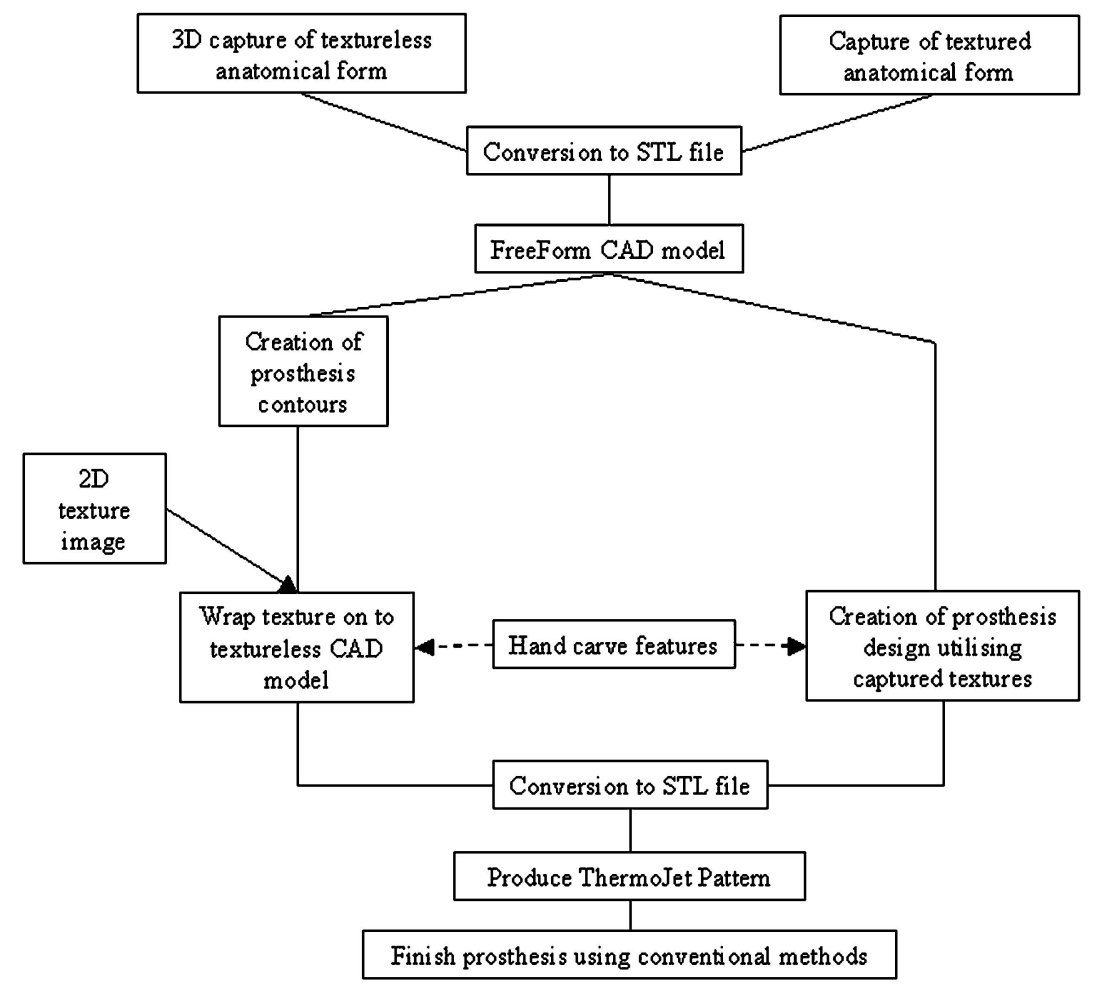

Fig. 2 Proposed routes for digital prosthesis design incorporating texture creation 
Table 1 Comparison of a selection of scanners used in the capture of anatomical surfaces

\begin{tabular}{|c|c|c|c|c|}
\hline Scanner & $\begin{array}{l}\text { Accuracy } \\
\text { (specified or measured) }\end{array}$ & $\begin{array}{l}\text { Resolution } \\
\text { (specified) }\end{array}$ & $\begin{array}{l}\text { Area of capture in } \\
x-y-z(\mathrm{~mm})\end{array}$ & $\begin{array}{l}\text { Speed } \\
\text { (specified or measured) }\end{array}$ \\
\hline $\begin{array}{l}\text { Steinbichler } \\
\text { Comet } 250\end{array}$ & $\begin{array}{l}\text { Manufacturer specification: } \\
\text { mean deviation } \sigma \pm 30 \mu \mathrm{m} \\
\text { volumetric accuracy } z \\
\pm 100 \mu \mathrm{m}\end{array}$ & $x-y$ point spacing $0.4 \mathrm{~mm}$ & $435 \times 350 \times 450$ & Tens of seconds \\
\hline $\begin{array}{l}\text { Inspeck Mega } \\
\text { Capturor } 2\end{array}$ & Not defined & $\begin{array}{l}0.3 \mathrm{~mm} \text { point spacing in } \\
x-y, 0.4 \mathrm{~mm} \text { in } z\end{array}$ & $\begin{array}{l}400 \times 320 \times 500(\mathrm{in} \\
\text { small field of view })\end{array}$ & $0.7 \mathrm{~s}$ \\
\hline $\begin{array}{l}\text { Breuckmann Opto } \\
\text { TOP-HE }\end{array}$ & $\begin{array}{l}\text { Calibrated to } 20 \mu \mathrm{m} \text { in this } \\
\text { study }\end{array}$ & $\begin{array}{l}0.15 \mathrm{~mm} \text { point spacing in } \\
x-y \text { with } 250 \text { FOV used in } \\
\text { this study. This will alter } \\
\text { with different FOV settings }\end{array}$ & $\begin{array}{l}200 \times 150 \times 100 \text { with } \\
250 \text { FOV used in this } \\
\text { study. This may be } \\
\text { altered }\end{array}$ & $<1 \mathrm{~s}$ \\
\hline $\begin{array}{l}\text { Konica-Minolta } \\
\text { Vivid } 910\end{array}$ & $\begin{array}{l}\text { Manufacturer specification: } \\
x \pm 220 \mu \mathrm{m}, y \pm 160 \mu \mathrm{m}, \\
z \pm 100 \mu \mathrm{m} \text { to the } z \text { reference } \\
\text { plane (TELE/FINE mode, } \\
\text { Minolta's standard) }\end{array}$ & $\begin{array}{l}0.69 \mathrm{~mm} \text { point spacing with } \\
14 \mathrm{~mm} \text { lens and subject at } \\
1350 \mathrm{~mm} \text { distance }\end{array}$ & $\begin{array}{l}445 \times 333 \text { in } x-y \text { with } \\
14.5 \mathrm{~mm} \text { lens }\end{array}$ & $\begin{array}{l}\text { Specified } 0.3 \mathrm{~s} \text { fast mode, } \\
2.5 \mathrm{~s} \text { fine mode }\end{array}$ \\
\hline $\begin{array}{l}\text { Cyberware, } 3030 \\
\text { head and face } \\
\text { colour 3D scanner }\end{array}$ & Not specified & Not specified & $\begin{array}{l}\text { Enough to cover entire } \\
\text { head to shoulders }\end{array}$ & Typically 17 s \\
\hline
\end{tabular}

other similar software do not represent an intuitive method for the manipulation of anatomical forms. Other CAD technologies such as ZBrush (Pixologic Inc.) and FreeForm ${ }^{\circledR}$ (SensAble Technologies Inc.) may provide a more suitable solution. Both FreeForm ${ }^{\circledR}$ and ZBrush allow complex three-dimensional forms to be manipulated and provide tools to add texture relief. FreeForm ${ }^{\circledR}$ has also been used in previous research to design facial prostheses $[\mathbf{8}, \mathbf{1 1}, \mathbf{1 2}]$ and utilizes a haptic interface that mimics the sensations of hand carving techniques used in conventional prosthesis sculpting. Table 2 highlights the features of potential software.

\subsection{RP reproduction of skin textures}

RP offers the most suitable solution to the production of a prosthesis pattern $[\mathbf{1 1}, \mathbf{1 2}]$. Computer numerically controlled (CNC) machining has also been used to create textures [18] but is not as well adapted to create fitting and undercut surfaces and has limited material choice and ability to create fine details over large areas. Table 3 compares a range of RP technologies capable of creating finely detailed, high-resolution textures. Of these, only the
ThermoJet ${ }^{\circledR}$ and Solidscape printing technologies are capable of producing parts in a material directly compatible with current prosthetic construction techniques. The Solidscape process utilizes a single jetting head to deposit a wax material, and another one to deposit a supporting material, which can be dissolved from the model. This produces very highresolution parts but is unfeasibly slow for facial prosthetics work. The ThermoJet ${ }^{\circledR}$ process deposits a wax material through multiple inkjet-style printing heads and is therefore much faster. Support structures are built concurrently and manually removed when the part is completed and cooled. The material is also softer than that used by Solidscape, making it more appropriate for manipulation using conventional prosthesis sculpting techniques. Although no accuracy specifications are given for the ThermoJet $^{\circledR}$, it is advertised as having a very high resolution and aimed at producing finely detailed parts.

\subsection{Suitable technologies identified}

Referring to the criteria outlined in section 3.1 and a review of potential technologies in sections 3.2 to

Table 2 Comparison of sample CAD software

\begin{tabular}{|c|c|c|c|}
\hline CAD software & $\begin{array}{l}\text { Intuitive ability to manipulate } \\
\text { anatomical forms }\end{array}$ & $\begin{array}{l}\text { Ability to apply texture } \\
\text { relief }\end{array}$ & $\begin{array}{l}\text { Ability to export suitable } \\
\text { data for fabrication }\end{array}$ \\
\hline FreeForm ${ }^{\circledR}$ & Yes - with haptic feedback & Yes - multiple methods & Yes \\
\hline ZBrush & Yes - without haptic feedback & Yes - multiple methods & Yes \\
\hline ArtCAM & No & Yes - embossing & Yes \\
\hline Rhino 3D & $\begin{array}{l}\text { Yes - less intuitive than } \\
\text { FreeForm or ZBrush }\end{array}$ & No & Yes \\
\hline
\end{tabular}


Table 3 Comparison of a range of high-resolution RP technologies

\begin{tabular}{|c|c|c|c|c|}
\hline RP technology & $\begin{array}{l}\text { Resolution } \\
\text { (manufacturer specification) }\end{array}$ & $\begin{array}{l}\text { Production volume } \\
\text { (manufacturer specification) }\end{array}$ & $\begin{array}{l}\text { Speed } \\
\text { (relative) }\end{array}$ & Material suitability \\
\hline $\begin{array}{l}\text { 3D-Systems, } \\
\text { ThermoJet wax } \\
\text { printing }\end{array}$ & $\begin{array}{l}300 \times 400 \times 600 \mathrm{dpi} \text {, approx. } \\
40 \mu \mathrm{m} \text { layer thickness }\end{array}$ & $254 \times 190 \times 200 \mathrm{~mm}$ & Fast & $\begin{array}{l}\text { Suitable - wax with melt } \\
\text { point of approximately } \\
80-90{ }^{\circ} \mathrm{C}\end{array}$ \\
\hline Solidscape T612 & $13-76 \mu \mathrm{m}$ layer thickness & $300 \times 150 \times 150 \mathrm{~mm}$ & Very slow & $\begin{array}{l}\text { Thermoplastic polymer } \\
\text { with melt point of } \\
95-110{ }^{\circ} \mathrm{C}\end{array}$ \\
\hline $\begin{array}{l}\text { Envisiontec, } \\
\text { Perfactory }\end{array}$ & $\begin{array}{l}90-148 \mu \mathrm{m} \text { pixel size, } \\
15-150 \mu \mathrm{m} \text { layer thickness }\end{array}$ & $\begin{array}{l}190 \times 152 \times 230 \mathrm{~mm} \text { to } \\
120 \times 96 \times 230 \mathrm{~mm}\end{array}$ & $\begin{array}{l}\text { Fast, up to } 25 \mathrm{~mm} / \mathrm{h} \\
\text { on } 0.1 \mathrm{~mm} \text { thick layers }\end{array}$ & $\begin{array}{l}\text { Unsuitable - thermoset } \\
\text { polymer }\end{array}$ \\
\hline $\begin{array}{l}\text { Objet Geometries, } \\
\text { Eden } 250\end{array}$ & $\begin{array}{l}600 \times 300 \times 1600 \mathrm{dpi}, 16 \mu \mathrm{m} \\
\text { layer thickness }\end{array}$ & $250 \times 250 \times 200 \mathrm{~mm}$ & Fast & $\begin{array}{l}\text { Unsuitable - thermoset } \\
\text { polymer }\end{array}$ \\
\hline $\begin{array}{l}\text { 3D-Systems, SLA } \\
\text { Viper }\end{array}$ & $\begin{array}{l}0.25 \mathrm{~mm} \text { beam diameter } \\
\text { (standard) or } 0.075 \mathrm{~mm} \text { (fine) }\end{array}$ & $\begin{array}{l}250 \times 250 \times 250 \mathrm{~mm} \text { standard } \\
125 \times 125 \times 250 \text { fine }\end{array}$ & Medium fast & $\begin{array}{l}\text { Unsuitable - epoxy } \\
\text { thermoset resin }\end{array}$ \\
\hline
\end{tabular}

3.4, the following technologies were selected for the pilot studies:

(a) FreeForm ${ }^{\circledR}$ CAD for its ability to manipulate complex forms and apply texture detail;

(b) ThermoJet printing for its ability to produce high-definition parts in a suitable material;

(c) Breuckmann fringe-projection scanning for its potential to capture anatomy with high accuracy, high resolution, and high speed.

\subsection{Case study hypotheses}

The literature and technology review suggested that the selected technologies are capable of capturing, manipulating, and reproducing textured prosthesis patterns. Three testable hypotheses were generated.

1. The scanning technology selected may be used to capture skin texture and wrinkle detail while also capturing sufficient anatomy to allow for digital prosthesis design.

2. The CAD techniques selected may be used to emboss skin texture like details to a scale identified by Lemperle et al.

3. The RP techniques selected may be used to produce textures to a visually convincing level.

\subsection{Assessment methods}

Prosthetists are primarily interested in achieving the visual effect of skin texture to ensure that a prosthesis is indistinguishable from the surrounding skin in casual observation. By definition, prostheses are oneoff custom-made appliances made to fit individual patients, with the aesthetic outcome and accuracy subjectively assessed by the prosthetist and subsequently the wearer. Visual analysis of the results was therefore used to test the hypotheses. Hypothesis 1 was tested by comparing dental stone models produced from conventional impression techniques with those from scan data and RP fabrication. Areas of the face that showed varying degrees of wrinkles were compared. Hypothesis 1 would be proved correct if the levels of detail visible on the scanned and RP-fabricated models showed no or insignificant loss of detail. Hypotheses 2 would be proved correct if the chosen CAD software was capable of creating texture relief to the scales identified by Lemperle et al. Hypothesis 3 would be proved correct if the texture relief was produced to a visually convincing level without interference from the layer stepping effects commonly exhibited by RP fabrication.

Two studies were designed to test the hypotheses.

\section{CASE STUDIES}

\subsection{Study 1 - using a two-dimensional texture image to generate three-dimensional relief on a CAD model}

\subsubsection{Producing the texture image}

A sample texture was manipulated to produce a highcontrast, black and white image using Photoshop software (Adobe Systems Inc.) [Figs 3(a) and (b)]. Images may be obtained from a database, a digital macrophotograph or impression, and a pad print of skin.

\subsubsection{Application of textures in CAD}

Blocks with a $25 \mathrm{~mm}$ diameter compound, convex surface on one side were created in FreeForm ${ }^{\circledR}$ with a fine, $0.1 \mathrm{~mm}$ edge definition. The convex block was designed to test the visible effect of stair stepping in the RP-produced patterns, since this becomes more evident on curved surfaces. 


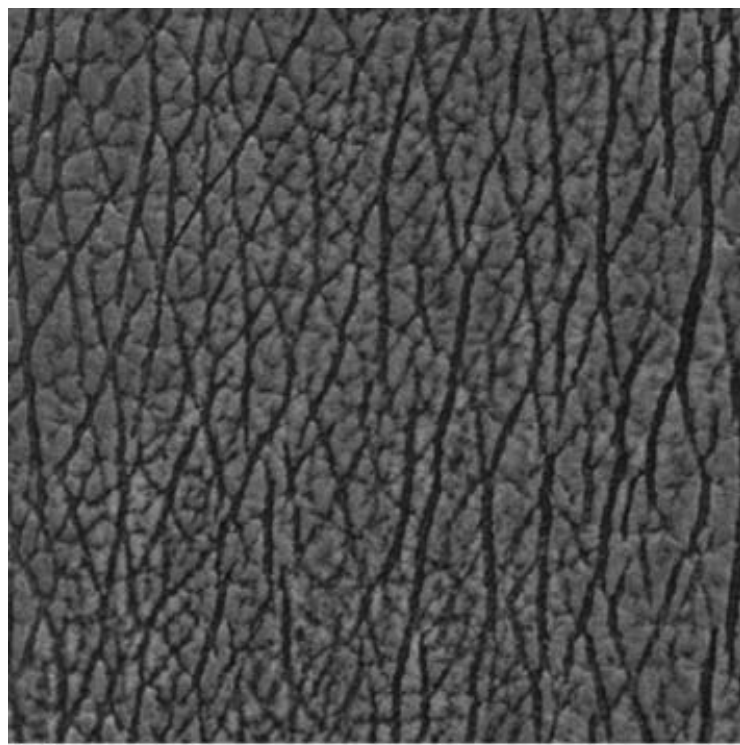

(a)

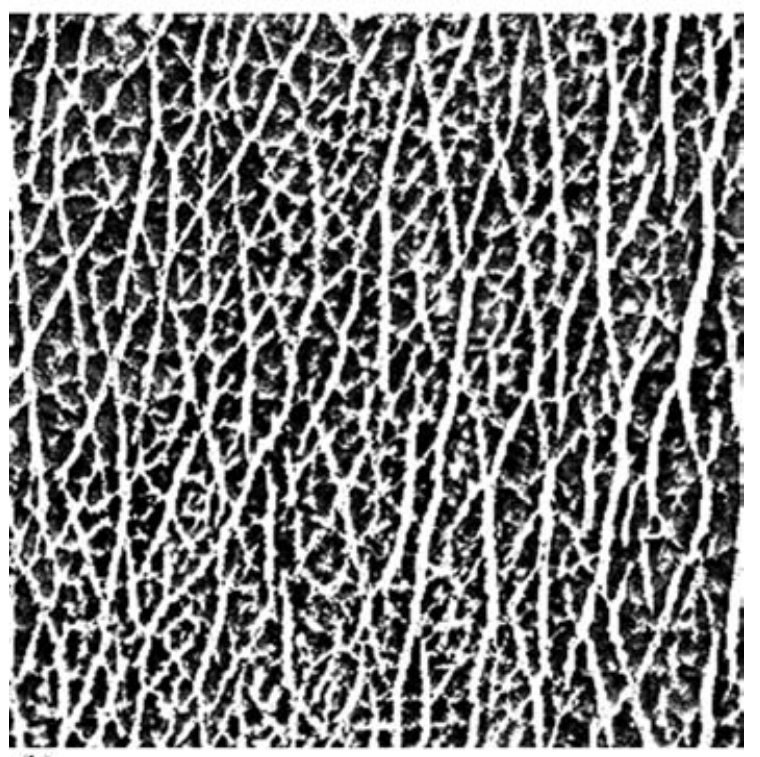

(b)

Fig. 3 (a) Skin texture image used in this study and (b) the manipulated, high-contrast version used to create the relief

A rectangular box enclosing a surface area was drawn on to the piece surfaces, and the 'emboss with wrapped image' tool was used to overlay the sample textures in the box. The 'emboss' option was used to set varying texture depths of $0.1,0.15,0.25,0.35$, 0.5 , and $0.8 \mathrm{~mm}$. These depths corresponded to the wrinkle depth scale and associated measurements in various facial areas developed by Lemperle et al. [15]. The actual emboss depth is determined by the image greyscale value; black will emboss to the full depth, light-grey will emboss less.

The scale settings were also used for arbitrary adjustment of the emboss density. The embossing may be previewed as either an image [Fig. 4(a)] or relief [Fig. 4(b)].

The 'ruler' function in FreeForm ${ }^{\circledR}$ may be used to validate the depth of textures by measuring the distance from an original smooth copy of the part to the grooves in the textured version.

\subsubsection{RP manufacture}

The blocks were manufactured using ThermoJet ${ }^{\circledR}$ printing with the textured surfaces facing upwards. All six patterns were built in less than $1.5 \mathrm{~h}$. The resulting parts can be seen in Fig. 5 .

\subsubsection{Study 1 results}

Study 1 proved hypotheses 2 and 3 correct. FreeForm ${ }^{\circledR}$ was capable of embossing textures to the depths chosen. All of the texture depths were visible on the ThermoJet ${ }^{\circledR}$ patterns. The layer stepping effect commonly exhibited by layer manufacture RP
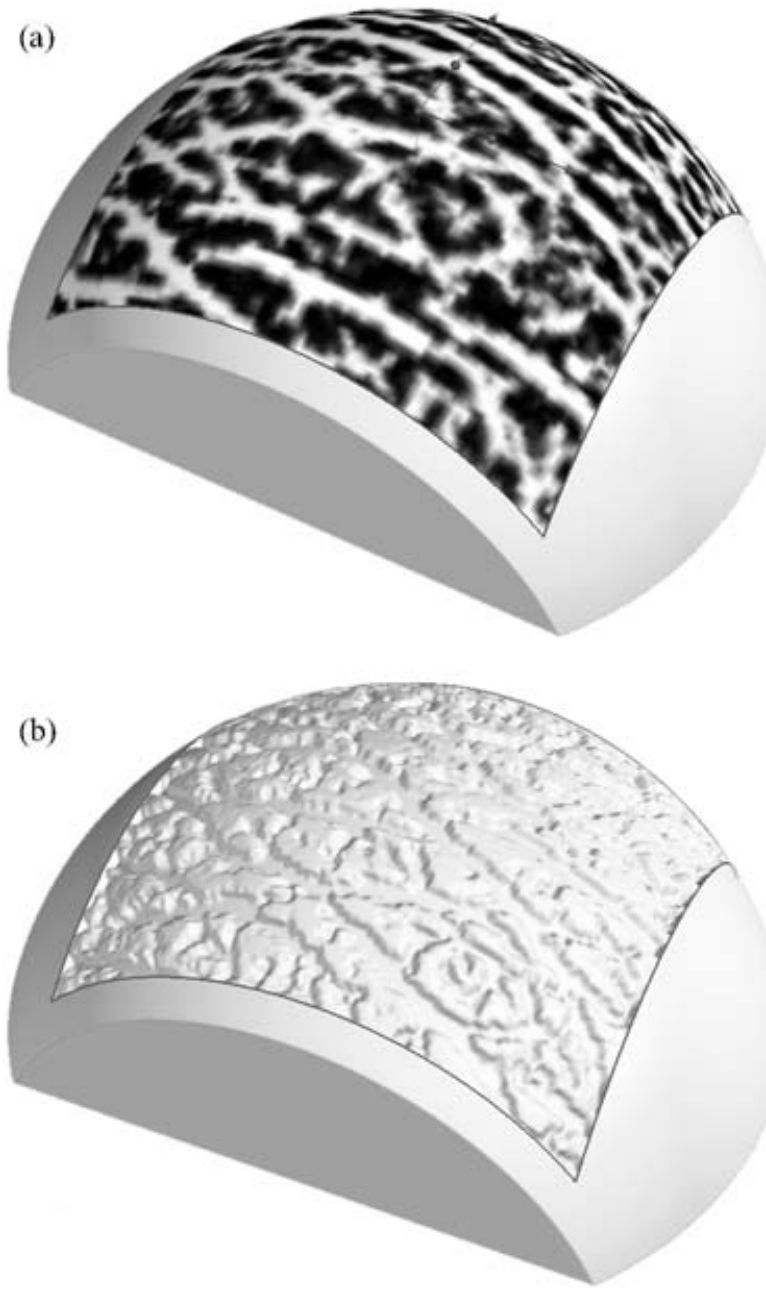

Fig. 4 (a) Previewing the image for embossing and (b) the relief created by the image 


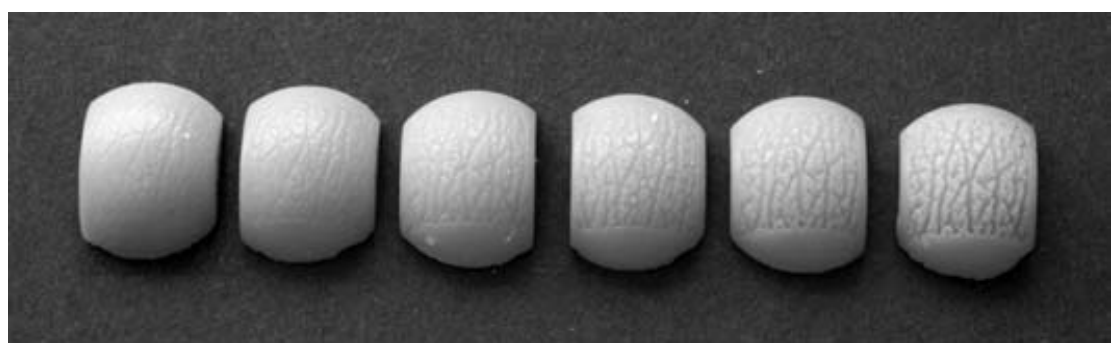

Fig. 5 Six ThermoJet ${ }^{\circledR}$-produced skin texture sample patterns

processes was not visible on the surface and did not interfere with the texture patterns. Textures would not, however, be well defined on down-facing surfaces owing to the dense support structure which, when removed, left a rough finish. This may be a problem if the technique were used in the production of complex prosthetic forms where all surfaces were on show, such as hands.

\subsection{Study 2 - using structured white light scanning to capture gross facial topography, wrinkles, and textures}

\subsubsection{Texture capture}

A Breuckmann Opto TOP-HE scanner with a single lens was used to capture a portion of a subject's face. The scanner was set up with a $250 \mathrm{~mm}$ field of view (FOV) and a focal distance of 845 and $150 \mathrm{~mm}$. This set-up was chosen because it was able to capture enough of the face to provide references when digitally designing a prosthesis, while still providing good close-up detail. Other settings may be used in order to capture greater levels of detail within a smaller FOV. This would, however, limit the usefulness of the data for subsequent prosthesis design. Calibration accuracy was within $20 \mu \mathrm{m}$, and approximately 1 million points were captured.

One scan was able to collect enough frontal face detail, but three were required in order to cover the facial features from ear to ear. Each scan took $0.8 \mathrm{~s}$ and required the subject to remain as still as possible in a relaxed pose. Once captured, the three sets of point cloud scan data were aligned to form one dataset and then converted into the three-dimensional polygon standard triangulation language (STL) file using the proprietary Breuckmann and Raindrop Geomagic Studio (Raindrop Geomagic Inc.) software. Optical scanners typically cannot capture surface detail through hair [5]. Therefore, minor hole filling was undertaken on part of the stitched STL file in order to create surfaces in areas the scanner was unable to capture, such as eyebrows and corners of the eye. The left side was left unmodified.
Impressions of the subject's right forehead and cheek were also made using a dental polyvinylsiloxane impression material and converted to dental stone models.

\subsubsection{CAD model and production}

The surface STL files were imported into FreeForm ${ }^{\circledR}$ using the 'thicken surface' setting to give a nominal thickness and make it a solid object. Figure 6(a) shows the areas captured by one scan, and Fig. 6(b) shows the area captured by three stitched scans. The figures also highlight areas that the scanner was unable to capture, such as the eyebrows, nostrils, and eyeballs. Minor gap filling work on the subject's right side has been undertaken in Fig. 6(b).

A section of the forehead and cheek corresponding to the areas from the polyvinylsiloxane impressions were exported as STL files and produced using ThermoJet ${ }^{\circledR}$ printing. Impressions were made of the ThermoJet $^{\circledR}$ models, and these were converted to dental stone models for comparison.

\subsubsection{Study 2 results}

Study 2 proved hypothesis 1 incorrect. The casts produced from the scan data showed visible and significant reduction in texture detailing, and only large wrinkle features remained (Fig. 7). This indicates that, although the ThermoJet ${ }^{\circledR}$ process is capable of producing patterns with sufficient detail, the stages of scanning, data processing, and CAD manipulation must be refined in order faithfully to reproduce finer skin textures.

\section{DISCUSSION}

The two techniques discussed may lend themselves to different prosthetic rehabilitation situations. Techniques applied in study 1 may be most suitable where a patient has already undergone a CT scan and three-dimensional CAD data are available, but texture detail must be added in order to achieve a 

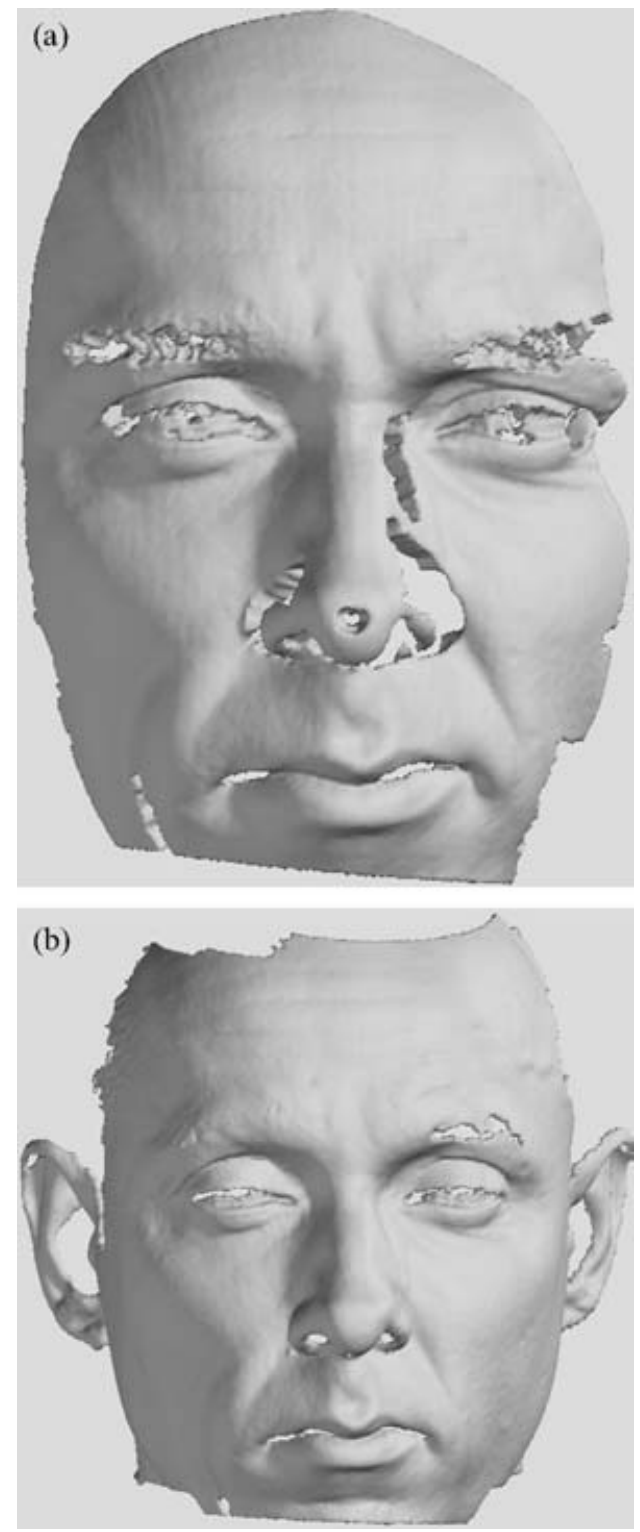

Fig. 6 (a) Area captured by a single scan and (b) the area captured by three scans

realistic result. Techniques applied in study 2 are likely to be more suitable where CT scanning is not appropriate, no previous scan has been undertaken, or the scan data that are available no longer provide an accurate representation of the facial contours.

The tools available in FreeForm ${ }^{\circledR}$ were well adapted to creating texture relief from twodimensional images. One possible limitation is large file size. In order to represent texture faithfully, large amounts of data are required. A high-resolution model setting that demands considerable computer processing power must be used in the CAD and subsequent export to STL file stages. While more modern, high-specification computers may be able to handle the large file sizes, it may make the process unmanageably slow for others. Further research is necessary in order to optimize the file size versus quality settings.

The Breuckmann non-contact scanner used in the present study was capable of capturing facial contours, but fine textures were not visible once the data had been fabricated. This may be due to a number of factors. Although scan times were of the order of $0.8 \mathrm{~s}$ and the positional accuracy was within $20 \mu \mathrm{m}$, slight facial movements during and between scans were likely to have distorted the detail captured. In addition, errors in the captured data are filtered in the subsequent software stages, which may further act to destroy fine details. Folds in the skin and undercut features, shiny surfaces, and hair are also difficult for light-based scanners to capture and require repair during the software stages, adding possible error. Addressing these limitations by adjusting the software and hardware parameters is likely to improve the capture of fine details. Simple methods such as preventing movement by supporting the subject's body may also improve the results.

The ThermoJet ${ }^{\circledR}$ process was capable of producing all of the texture samples faithfully and did not exhibit the stair stepping effect that some other RP processes display. This ability, combined with the suitable material properties, demonstrates how the process may be integrated into digital prosthesis design and production techniques that are compatible with conventional hand crafting techniques.

\subsection{Study limitations}

This paper has indicated that CAD and RP processes may be used to generate visually convincing levels of texture detailing, but has not quantified the capabilities of each technology stage.

\section{CONCLUSIONS}

This paper has addressed the aims identified in the introduction. Levels of texture detailing that may be incorporated into digital prosthesis design were identified. Furthermore, suitable methods of applying and reproducing these levels of detail to a visually convincing degree were evaluated. However, further research is required to address the limitations of texture capture using optical scanning methods. Research should concentrate on quantifying the specifications required to incorporate texture capture, manipulation, and creation into digital prosthesis design and evaluate effectiveness in patient case studies. Methods such as profilometry could be 


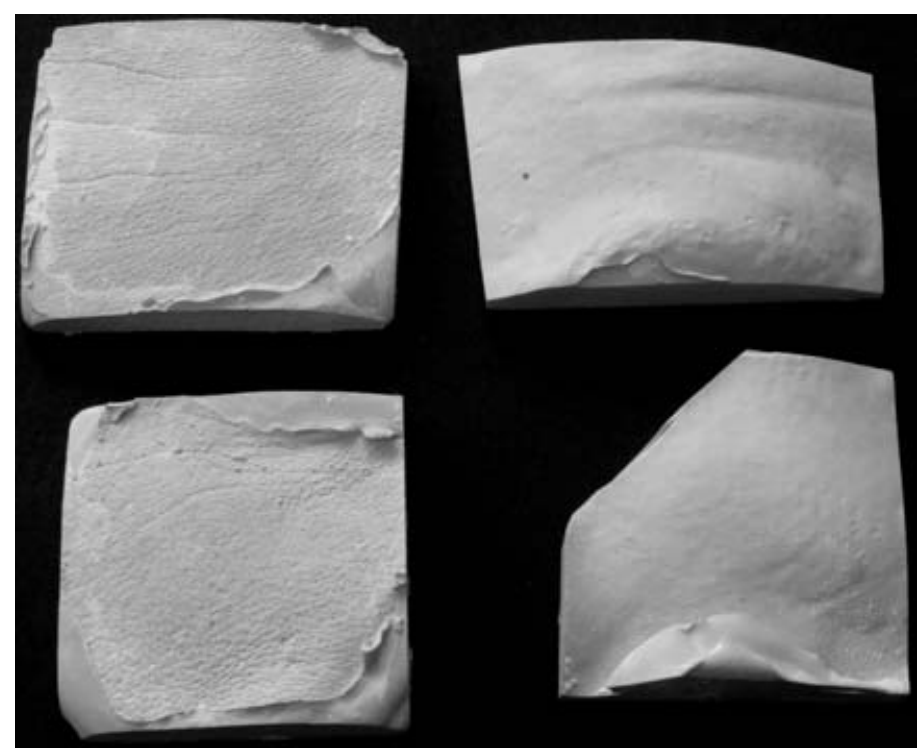

Fig. 7. Forehead impression (top left), ThermoJet ${ }^{\circledR}$ forehead impression (top right), cheek impression (bottom left), and ThermoJet ${ }^{\circledR}$ cheek impression (bottom right)

applied to measure subject texture and quantify the capabilities of digital technologies post prosthesis production. The authors also intend to develop a specification against which technologies may be assessed and towards which they may be developed.

\section{REFERENCES}

1 Thomas, K. Maxillofacial prosthetics, 1994, p. 13 (Quintessence Publishing, London).

2 Cheng, A. C., Wee, A. G., Li, J. T., et al. A new prosthodontic approach for craniofacial implantretained maxillofacial prostheses. J. Prosthet. Dent., 2002, 88(2), 224-228.

3 Wolfaardt, J., Sugar, A., and Wilkes, G. Advanced technology and the future of facial prosthetics in head and neck reconstruction. Int. J. Oral Maxillofacial Surg., 2003, 32(2), 121-123.

4 Coward, T. J., Watson, R. M., and Wilkinson, I. C. Fabrication of a wax ear by rapid-process modelling using stereolithography. Int. J. Prosthodont., 1999, 12(1), 20-27.

5 Bibb, R., Freeman, P., Brown R., et al. An investigation of three-dimensional scanning of human body surfaces and its use in the design and manufacture of prostheses. Proc. IMechE, Part H: J. Engineering in Medicine, 2000, 214(H6), 589-594.

6 Cheah, C. M., Chua, C. K., Tan, K. H., et al. Integration of laser surface digitizing with CAD/ CAM techniques for developing facial prostheses. Part 1: design and fabrication of prosthesis replicas. Int. J. Prosthodont., 2003, 16(4), 435-441.

7 Cheah, C. M., Chua, C. K., and Tan, K. H. Integration of laser surface digitizing with CAD/ CAM techniques for developing facial prostheses. Part 2: development of molding techniques for cast- ing prosthetic parts. Int. J. Prosthodont., 2003, 16(5), 543-548.

8 Verdonck, H. W. D., Poukens, J., Overveld, H. V., et al. Computer-assisted maxillofacial prosthodontics: a new treatment protocol. Int. J. Prosthodont. 2003, 16(3), 326-328.

9 Reitemeier, B., Notni, G., Heinze, M., et al. Optical modeling of extraoral defects. J. Prosthet. Dent., 2004, 91(1), 80-84.

10 Tsuji, M., Noguchi, N., Ihara, K., et al. Fabrication of a maxillofacial prosthesis using a computer-aided design and manufacturing system. J. Prosthodont., 2004, 13(3), 179-183.

11 Eggbeer, D., Evans, P., Bibb, R. The application of computer aided techniques in facial prosthetics. In Proceedings of 6th International Congress on Maxillofacial Rehabilitation, 2004, p. 55.

12 Evans, P., Eggbeer, D., and Bibb, R. Orbital prosthesis wax pattern production using computer aided design and rapid prototyping techniques. $J$. Maxillofacial Prosthetics and Technol., 2004, 7, 11-15.

13 Piérard, G. E., Uhoda, I., and PiérardFranchimont, C. From skin microrelief to wrinkles. An area ripe for investigation. J. Cosmetic Derm., 2003, 2(1), 21-28.

14 Hashimoto, K. New methods for surface ultrastructure: comparative studies scanning electron microscopy and replica method. Int. J. Derm., 1974, 13(6), 357-381.

15 Lemperle, G., Holmes, R. E., Cohen, S. R., et al. A classification of facial wrinkles. Plast. Reconstr. Surg., 2001, 108(6), 1735-1750.

16 Holman, C. D. J., Armstrong, B. K., Evans, P. R., et al. Relationship of solar keratosis and history of skin cancer to objective measures of actinic skin damage. Br. J. Derm., 1984, 110, 129-138.

17 Park, S. G., Kim, Y. D., Kim, J. J., et al. Two possible 
classifications of facial skin type by two parameters in Korean women: sebum excretion rate (SER) and skin surface relief (SSR). Skin Res. Technol., 1999, 5, 189-194.

18 Yean, C. K., Kai, C. C., Ong, T., et al. Creating machinable textures for CAD/CAM Systems. Int. J. Advd Mfg Technol., 1998, 14, 269-279.

\section{APPENDIX}

\section{Noted software and technology developers}

FreeForm ${ }^{\circledR}$ Software. SensAble Technologies, Inc., 15 Constitution Way, Woburn, Massachusetts 01801, USA. www.sensable.com

ZBrush software. Pixologic, Inc., 320 West 31st Street, Los Angeles, California 90007, USA. www.pixologic.com

Artcam software. Delcam plc, Small Heath Business Park, Birmingham B10 OHJ, UK. www.delcam.com

Rhino 3D. 3670 Woodland Park Ave N, Seattle, Washington 98103, USA. www.rhino3d.com

Photoshop software. Adobe Systems, Inc., 345 Park Avenue, San Jose, California 95110-2704, USA. www.adobe.com

3D Studio software. Discreet (part of Autodesk, Inc.), 10 Duke Street, Montreal, Quebec H3C 2L7, Canada. http://usa.autodesk.com
Steinbichler Comet 250 scanner. Steinbichler Optotechnik Gmbh, AM Bauhof 4, D-83115 Neubeuern, Germany. www.steinbichler.de Inspeck scanner. 3530 St-Laurent Blvd, Suite 303, Montreal H2X 2V1, Canada. www.inspeck.com

Breuckmann scanners. Breuckmann Gmbh, Torenstr. 14, 88709 Meersburg, Germany. www.breuckmann.com

Konica Minolta 910 scanner. Konica Minolta Sensing Americas, Inc., 101 Williams Drive, Ramsey, New Jersey 07446, USA. www.konicaminolta.com

Cyberware 3030 scanner. 2110 Del Monte Avenue, Monterey, California 93940, USA. www.cyberware.com

Raindrop Geomagic software. Raindrop Geomagic, Inc., P.O. Box 12219, Research, Triangle Park, North Carolina 27709. www.geomagic.com ThermoJet ${ }^{\mathbb{R}}$ and Stereolithography RP modelling system. 3D Systems, 26081 Avenue Hall, Valencia, California 91355, USA. www.3dsystems.com

Solidcape RP systems. Solidscape, Inc., 316 Daniel Webster Highway, Merrimack, New Hampshire 03054-4115, USA. www.solid-scape.com

Perfactory RP modelling system. Envisiontec GmbH, Elbestrasse 10, D-45768 Marl, Germany. www.envisiontec.de

Objet 250 RP system. Objet Geometries Ltd, 2 Holzman St, Science Park, PO Box 2496, Rehovot, Israel. www.2objet.com 